\title{
Friction and Wear Performance of Gold and Gold Alloy Films
}

\author{
Yukio Miyakawa \\ National Aerospace Laboratory, Tokyo, Japan
}

The tribological properties of gold and gold alloy coatings are of interest from two main points of view. In the electronics industry they influence the service lifetimes of electrical connectors and sliding contacts. In the aerospace industry they dictate the use of gold on moving metal parts as a solid film lubricant. Current knowledge of these properties is reviewed here with particular emphasis on this latter type of applications.

\begin{abstract}
When perfectly clean metal surfaces slide against one another there is a tendency for the metals to adhere and bond together. In air, however, most metals are covered with a film of oxide, and even where this film is destroyed by mechanical action it re-establishes itself rapidly. Welding together of the metals does not therefore normally occur. At low pressures, such as those that prevail in outer space, surface films that are dislodged from sliding parts by movement, vibration or other agencies cannot reestablish themselves and the risk that the parts will weld together is great. Moreover, under such conditions, normal lubricants such as oils, greases, polymers, etc. may be removed by evaporation or, in outer space, be affected by radiation.
\end{abstract}

Not all metals behave alike in such situations, and with metals of low shear strength, of which gold is one, the cold welding which occurs under high vacuum is not serious, the metal acting effectively as a solid phase lubricant. It is against this background that the use of gold as a solid film lubricant on space equipment with moving parts has developed. An advantage of gold over alternative metals or substances that may be envisaged as solid lubricants is its inertness during storage under normal atmospheric conditions prior to use. Items which may be lubricated by gold films are many and include, for example, camera shutters, filter changers, focusing and zoom mechanisms, radar antennae and solar paddles.

\section{Factors Affecting the Behaviour of Gold Films}

The effectiveness of gold films in reducing friction and wear of moving parts depends upon many factors of which some are interrelated. Adhesion of the film to its substrate, for example, plays a significant role, and while certain techniques of deposition inherently lead to better bonding of deposits than others, the nature of the substrate is an important consideration. Similarly, the degree to which gold may tend to adhere to an uncoated part sliding against it will affect its performance. This latter aspect, in turn, may depend on the nature of any alloying elements in the gold and on conditions such as testing environment. From this, it will be apparent that the results of friction and wear tests on gold and gold alloy films can be interpreted validly only in the light of a variety of factors. These are discussed in what follows.

\section{Method of Deposition}

The properties of electrodeposited gold coatings are very dependent on the nature of the electrolytic bath and the operating conditions used, and are particularly affected by the co-deposition of base metal impurities or carbonaceous materials where this occurs. Such problems do not arise to the same extent when thin gold films are deposited by vacuum evaporation or sputtering, but nevertheless process details have emerged as highly significant. A disadvantage of these latter techniques, for example, is that throwing power is low or extremely small so that complex geometrical shapes cannot be coated without rotating the object relative to the source. From this point of view the ion plating process developed by Mattox (1) has distinct advantages. The relative merits of this and the evaporation and sputtering techniques have been defined in a series of studies by Spalvins, Ohmae and Miyakawa and their co-workers.

\section{Adhesion of the Film to the Substrate}

An important factor governing the durability and strength of a gold film under frictional stress is the adhesion between it and the substrate metal. Spalvins and Buckley (2) found that diffusion across the gold/substrate interface, or better still, embedding of gold in the substrate to create an interfacial zone of 
graded composition is most desirable from the standpoint of friction and lubrication. Thus, films formed by ion plating gold onto a nickel-chromium alloy substrate were characterized by a highly embedded type of interface and exhibited lower friction and had longer wear lives than films formed by vacuum evaporation of gold onto the same substrate, even though this was heated to aid diffusion across the interface. In tune with this, Ohmae et al. (3), in studies of the prevention of fretting by gold coatings on a 0.25 per cent carbon steel substrate, found that resistance to fretting under atmospheric conditions was greatest with ion-plated, less with sputtered and least with evaporated films. Adhesion tests revealed also that the ion-plated films were more strongly bonded to the substrate than either vacuumevaporated or sputtered films. Because of the higher kinetic energies of the particles striking the substrate during ion plating, this finding was not unexpected.

The very great importance of substrate temperature in determining the adhesion and other properties of vacuum-deposited thin films is emphasized by the work of Miyakawa et al. (4). These authors compared the behaviour in sliding friction of gold films ionplated onto 52100 steel or 304 stainless steel with that of films deposited by vacuum evaporation and sputtering. They found that the strength of bonding to the substrate was highly dependent in each case upon the temperature of the substrate surface during the deposition process, to the extent that there was little difference in lubrication performance between ionplated and evaporated films deposited under optimum conditions. It was concluded that such performance depends primarily on the strength of the bond between the film and the substrate and that this is determined mainly by the degree of diffusion across the interface. Under optimum conditions such diffusion can compensate for the lower kinetic energies with which gold particles strike the substrate surface in the vacuum evaporation process.

\section{Sliding Metals Combination}

Takagi and Liu (5) investigated the effectiveness of electrodeposited gold films in reducing friction and wear under atmospheric conditions. Sliding friction between a steel rider and a steel flat was effectively reduced by plating the latter with gold, but the lubrication performance was affected by other factors of which the most important was the nature of the rider metal. Thus, a rider made of $440 \mathrm{C}$ stainless steel, sliding on a gold-plated 52100 steel disk, usually exhibited much lower friction than a 52100 steel rider.

Similar observations were made by Miyakawa et al. (4) using ion-plated gold films. On the one hand, the friction coefficient of a 52100 steel rider sliding on a gold ion-plated 52100 steel disk was high and wear life was short in dry air. On the other hand, a $440 \mathrm{C}$ steel rider gave low friction and much longer wear life. The difference in behaviour between the two steel riders may be ascribed to the difference between their affinities for gold. With a 52100 steel rider, shearing of the gold film occurs as the result of its strong adherence to that steel, and this naturally leads to a higher friction coefficient and shorter wear life. When using a $440 \mathrm{C}$ stainless steel rider, the presence of a layer of chromium oxide on its surface inhibits adhesion of gold to the stainless steel. It was also found that while the coefficient of friction between a gold-plated $440 \mathrm{C}$ steel disk and a $440 \mathrm{C}$ steel rider was low, the wear life of the combination was shorter than that of a $440 \mathrm{C}$ steel ball sliding on a gold-plated 52100 steel disk. This indicates that although a layer of chromium oxide on a $440 \mathrm{C}$ steel rider is effective in lowering the friction between it and a gold film, it also weakens the bond between the gold film and a substrate made of the same steel. Miyakawa et al. concluded that effective lubrication is realized only when the adhesion between the gold film and the substrate metal is strong and that between the gold film and the rider metal is weak.

\section{Film Thickness}

The thickness of coatings also exercises an important influence on their friction and wear properties. Thus, Takagi and Liu (6) investigated the behaviour of electrodeposited films of gold, silver, copper, nickel and two gold alloys, with thicknesses ranging between 0.2 and $20 \mu \mathrm{m}$, in a rub-shoe machine operated under severe conditions in air. The assembly consisted of a 52100 or $440 \mathrm{C}$ steel rectangular block rubbing against a 52100 or $440 \mathrm{C}$ steel ring coated with the film to be evaluated. Lubrication by gold coatings was most effective at thicknesses of at least 5 to $20 \mu \mathrm{m}$. Although gold alloys, silver and copper deposited to the proper thickness improved several hundred times the wear life of the assembly tested, they were far less effective than pure gold.

\section{Environment}

Miyakawa et al. (4) investigated the influence of the gaseous environment on sliding friction properties of both gold and silver ion-plated films. Gold films had lower coefficients of friction and much longer wear lives in vacuum than in dry air. Silver films showed higher friction and much shorter wear lives than the gold films in dry air, and the influence of the sliding metals combination was small. Silver films, however, gave much better performance in vacuum than the gold films. The difference is to be attributed to the presence of oxide films on silver in dry air. These adhere strongly to oxide films present on 52100 and $440 \mathrm{C}$ steels with the result that shearing occurs 


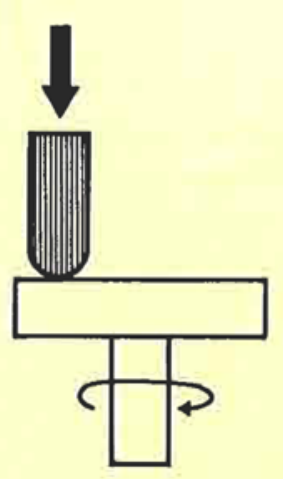

Rider-on-flat (undirectional)

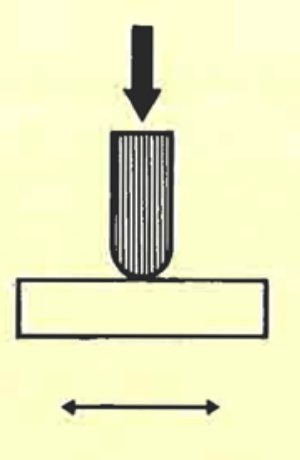

Rider-on-flat (reciprocating)

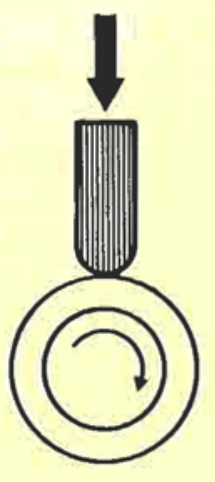

Rider-on-ring

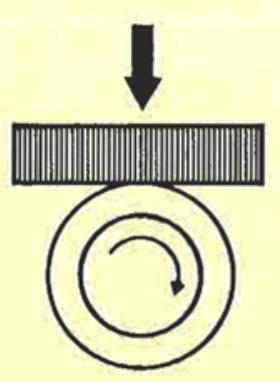

Rub-shoe on ring

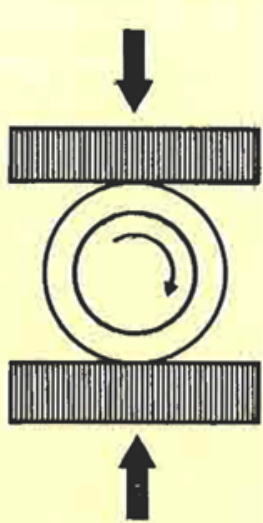

Dual rub-shoe on ring

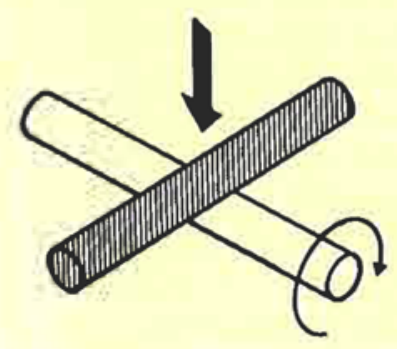

Crossed cylinders

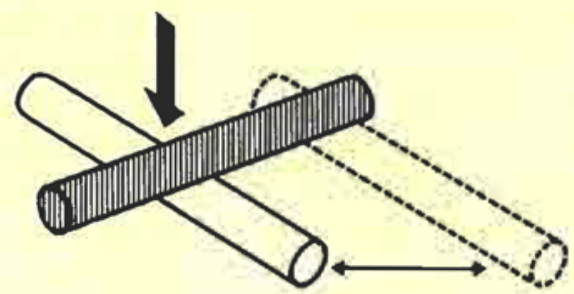

Crossed cylinders the lower nember moves back and forth at a $45^{\circ}$ angle)

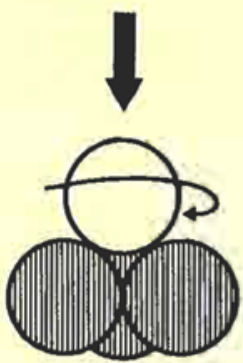

Ball on three balls (four ball)

Many procedures have been developed for the evaluation of the friction and wear behaviour of lubricated and unlubricated inaterials. Some of the more common testing configurations are illustrated schematically here with the stationary members indicated by shading, the directions of motion indicated by thin arrows and the directions in which the load is applied indicated by bold arrows

within the silver film. Under vacuum, however, oxide films are not well developed on silver, which therefore does not adhere so strongly to the steel rider. Similar results have been obtained by Begelinger and De Gee (7) who used a silver rider against a ring of SAE 1045 steel. These authors found that the replacement of a high purity argon test atmosphere by a mixture of argon and oxygen caused an instantaneous increase in friction, followed by local transfer of silver to the steel ring and a high rate of wear. This strongly suggests that the formation of thin films of iron oxide on the ring was responsible for increased adhesion and metal transfer. These results indicate that although the lubrication performance of silver is superior to that of gold in vacuum or an inert atmosphere, the position is reversed in air because of the oxide films which form on silver under these conditions.

\section{Friction and Adhesion between Gold and Other Materials}

The frictional behaviour of gold against a variety of materials has been investigated by Buckley (8) with a rider-on-flat apparatus. He studied, for example, the frictional properties of gold in contact with platinum group metals. These properties are of interest in regard to the extensive use of such metals in electrical contacts - of both the make-and-break and sliding types - in which they are generally used against gold, silver, copper or their alloys. Gold was found to be transferred to all the platinum group metals in vacuum, and their coefficients of sliding friction with gold were in the order:

$$
\mathrm{Pt}>\mathrm{Pd}>\mathrm{Ru}=\mathrm{Rh}>\mathrm{Ir}
$$

the metals exhibiting the highest friction being the most active chemically. 
In the case of Group IV elements, Buckley found that the coefficient of friction was three times greater for gold sliding on a germanium $\{111\}$ surface than for gold sliding on a silicon $\{111\}$ surface in vacuum (9). The behaviour of the more metallic elements of the group, tin and lead, was also compared to that of the more covalently bonded elements silicon and germanium. For these tests, the elements were ion-plated onto nickel and studied in contact with gold in vacuum. Silicon and germanium showed lower frictional forces than the more metallic lead, and germanium adhered less strongly than the more metallic tin (10). In similar studies, using films of titanium, chromium, iron and platinum sputtered onto quartz or mica substrates, it was found that the friction coefficients with gold decreased as the $d$ bond character of the metal increased and depended upon adhesion across both the film/substrate and rider/film interfaces (11). Friction between gold and pyrolytic graphite, pyrolytic boron nitride and glass respectively has also been investigated (12), as has that between gold and copper, copper-aluminium alloys and iron in vacuum (13).

In the latter studies, Buckley found that the force required to fracture adhesive bonds of given configuration between gold and copper surfaces was $0.8 \mathrm{mN}$ for an applied load of $0.2 \mathrm{mN}$. With the addition of 1.0 atomic per cent aluminium to the copper, the adhesive force of the gold to the copper in bonds of the same configuration increased fivefold to $4.4 \mathrm{mN}$. On the basis of solid solubility, gold would be expected to have a greater affinity for copper than for aluminium. However, adhesion measurements indicated much stronger bonding of gold to aluminium and aluminium-containing copper alloys than to pure copper. Despite the very limited miscibility of gold and iron, adherence of gold to a clean iron surface was also found to be very strong; in experiments similar to those performed with gold and copper the adhesion force was $0.5 \mathrm{mN}$ for an applied load of $0.2 \mathrm{mN}$. Buckley concluded that bonding forces depend on the chemical activity of the metal in contact with gold rather than on its solubility in gold. Fujiwara (14) investigated the effects of surface contamination, tangential displacement, contact operation and specimen temperature on the adhesion of gold to itself in a crossed cylinder assembly tested under vacuum. The adhesion force was reduced by an adsorbed film of $\mathrm{H}_{2} \mathrm{O}$ or $\mathrm{CO}$ some nanometers in thickness, it increased with tangential displacement and decreased with repeated contact operation. It also increased with temperature in the range 20 to $350^{\circ} \mathrm{C}$, but surface contamination was not removed significantly under these conditions. Data on the relationships between the amount of gold transferred and the real contact area, and those between the amount of gold transfer- red and the adhesion force have also been reported by Fujiwara (15).

\section{Alloying Additions to Gold}

Pure gold is often too soft to provide wear resistance, but its lubrication and wear properties can be improved by addition of an alloying element. Fujiwara (16) showed that silicon, whether introduced on the gold surface as a contaminant or as an alloy component, was effective in preventing adhesion of a gold rider on a gold flat in air. The formation of silicon oxide prevented direct metallic contact. De Gee (17) found that in pure argon the behaviour of friction couples consisting of riders made of goldsilver alloys and tested agaist a SAE 1045 steel ring was determined by the silver contents of the alloys, silver-rich alloys showing excellent running properties in sliding contact with steel and gold-rich alloys showing severe scoring. Solomon and Antler (18) investigated the effect of load and of thickness of gold, gold-silver and gold-nickel alloys electrodeposited on rider and flat copper surfaces in air. They found that beyond a critical thickness (depending on the load and the substrate material) the resistance to wear increased markedly. For example, under a load of $100 \mathrm{~g}$, long life was achieved with a coating thickness of $5 \mu \mathrm{m}$ or more for gold-nickel, and of $10 \mu \mathrm{m}$ or more for gold-silver. The durability of gold-nickel was found superior to that of pure gold and gold-silver.

Miyakawa et al. (19) found that an electrodeposit of gold-cobalt alloy gave much lower friction and longer wear life in air than electrodeposited or ion-plated pure gold films. Abbott and Bartlett (20) have reported on the metallurgical and other characteristics required for advanced, high reliability, low energy, sliding contact systems. Their experiments were performed on contacts mounted in a $90^{\circ}$ crossed cylinder configuration with one member submitted to reciprocating sliding over a $1 \mathrm{~cm}$ wear track. All of the wrought gold alloys studied in this manner showed high friction $\left(\mu_{\mathrm{k}}=1.2\right.$ to 2.0$)$ and wear rates, both in air and vacuum. Several series of gold-cobalt electrodeposits, however, showed much lower friction and wear, and electrical noise levels were low compared to those in contacts using wrought alloys. The improved performance of these electrodeposited alloys was attributed to a unique surface chemistry consisting of an organic 'lubricant' film co-deposited with the coatings.

Buckley (21) has investigated the influence of orderdisorder transformations in copper-gold alloys on their friction characteristics in vacuum. He found that the friction coefficients for ordered $\mathrm{Cu}_{3} \mathrm{Au}$ and $\mathrm{CuAu}$ riders sliding on $440 \mathrm{C}$ stainless steel disks were less than those for the corresponding disordered alloys. The copper/10 atomic per cent gold alloy, 
Stationary rider with prow after unlubricated sliding of gold specimens in a rider-on-flat apparatus. The prow is the large nonnd of transfer metal from the llat which projects against the direction of sliding of the Iatter and separates the contact nembers $\quad x 30$

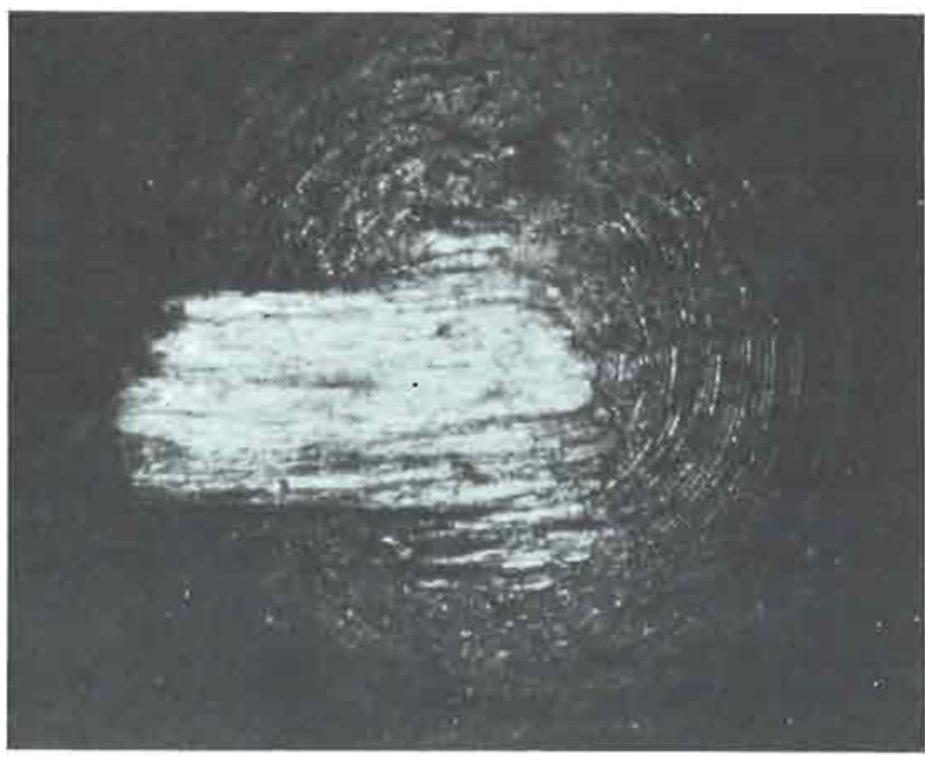

Prow formation and the subsequent transition to wear of the rider are not unique to the rider-on-flat geonetry. Any nember having the smaller area involved in sliding acts as does the the rider. Thus, in apparatus having contact menubers in a crossed cylinder configuration, as illustrated lere by a brush wire from an instrunent slip ring, a prow forms on the brush member
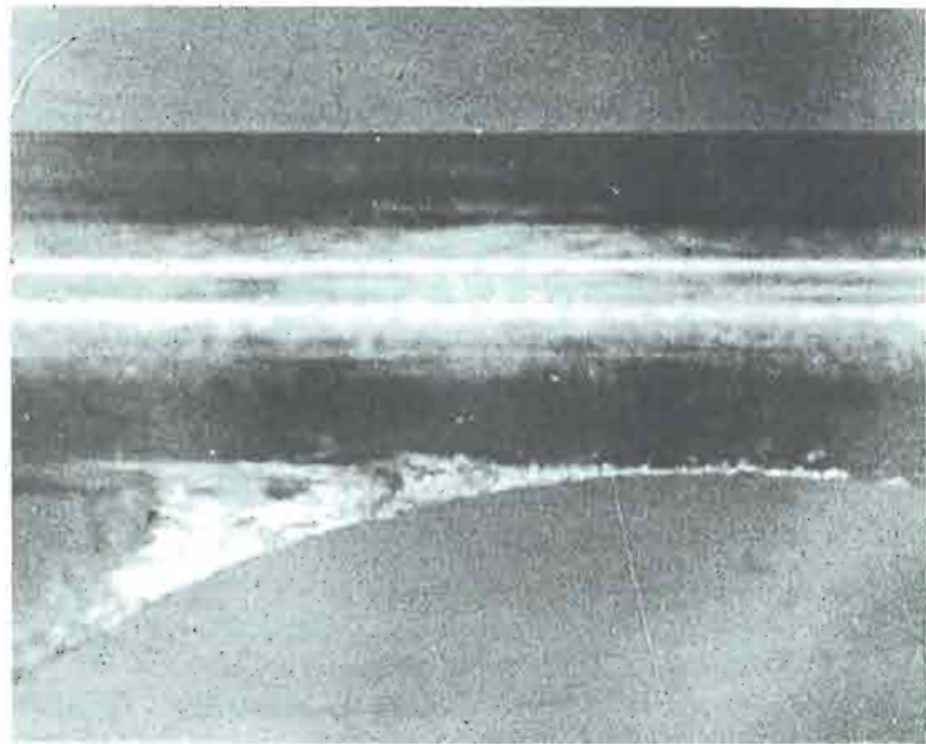

In adhesive wear by prow formation, metal is initially transferred from the contact member with the larger surface traversed in sliding (flat) to that with the smaller surface (rider). Prows are then lost by back-transfer to the flat, but new prows immediately re-form. This occurs repeatedly in repeat-pass sliding until the flat is entirely covered with back-trausfer material. A transition then ocenrs to a second process in which wear of the rider commences, the net direcition of netal transfer being that of rider to flat

Photographs by courtesy of $M$. Antler, Bell Laboratories, Columbus, OH.

which exists in the disordered state only, did not display any marked change in friction coefficient after being submitted to treatments that would have caused ordering in the other copper-gold alloys.

\section{Temperature}

Miyakawa et al. (4) found that ion-plated gold films failed to reduce the friction between steel surfaces in vacuum above about $200^{\circ} \mathrm{C}$. They observed that for effective lubrication above this temperature, it was necessary to prevent diffusion of the gold into the substrate metal. Enomoto et al. (22) showed that this could be achieved by the deposition of a layer of molybdenum between a stainless steel substrate and a gold film ion-plated onto it. This was so effective as a diffusion barrier that the gold film continued to act as a lubricant up to $600^{\circ} \mathrm{C}$. Thornton and Wolanski, and Turns (23) investigated the use of binary gold alloys to provide lubrication from room temperature up to $620^{\circ} \mathrm{C}$. Coated T-1 steel rings were tested on a rub-shoe machine with two $\mathrm{T}-1$ steel rub-shoes. Of the binary alloys of gold with ruthenium, rhenium and molybdenum, the latter had the best friction and wear characteristics in air. Partial oxidation of the molybdenum in the gold appeared to assist lubrication at $315^{\circ} \mathrm{C}$ and the effect increased up to $620^{\circ} \mathrm{C}$. 


\section{Wear Mechanisms of Gold}

Wear of gold is of two main types: adhesive wear and fatigue wear. Antler (24), who made extensive studies of the wear behaviour of gold, gold alloys and various other metals, reported that prow formation is a severe adhesive wear process that is characteristic of unlubricated, soft, ductile metals such as gold. When contact members are unsymmetrical, some metal is transferred from that with the larger surface traversed in sliding to that with the smaller such surface, for example from flat to rider. The transferred metal which adheres to the smaller member grows in quantity and projects forward, prow-like, against the rotating flat. The prow consists of severely work-hardened metal from the flat, but the rider itself does not wear. Prow formation also occurs with dissimilar metals, provided that the unworn flat is not excessively harder than the unworn rider. An example of such system is a gold rider on platinum flat. If the rider always traverses virgin metal, prow formation continues indefinitely. Conversely, if the rider traverses the same track repeatedly, prow formation eventually ceases and the rider begins to wear. There is a loaddependent roughness of the flat above which prow formation does not occur; sliding is then accompanied by rider wear from the start. The critical roughness is between 0.6 and 1.2 um centre line average (CLA) for wrought pure gold under a load of $100 \mathrm{~g}$ and diminishes with decrease of load. The sliding behaviour of gold electrodeposits is often different from that of wrought gold, and Antler could interpret this observation by isolating controlling factors such as structure, topography, or hardness. Whether sliding led to prow formation or rider wear depended on the surface texture of deposits. A gold-silver electrodeposit showed relatively low friction and high wear. This was associated with prow formation in which an initially formed prow persisted for an entire run and acted like a cutting tool to produce a deep narrow track in the flat. Hard gold electrodeposits also showed prow formation, though the mass loss from the flats was less than it was with other electrodeposits which Antler studied. In the case of a gold-cadmium deposit, preferential wear of the rider occurred and little debris was produced.

Soda et al. (25) have analyzed the wear process from an entirely different viewpoint. From experiments on the wear behaviour of gold, copper and nickel in a rider-on-flat apparatus operated under varying normal load, sliding velocity and atmospheric pressure, they concluded that wear is caused by fatigue fracture in the sliding surfaces. They found that the mean size of the wear fragments is quantitatively related to the thickness of the plastically deformed substrate layer, irrespective of the experimental conditions. From this observation, an understanding of the process of wear fragment formation was obtained. As a result of the repetitive action of normal and friction forces, plastic flow of material occurs in the substrate. Cracks then extend along the line of flow and wear fragments are liberated. Variations in the normal load and sliding velocity alter the wear pattern because of the changes they induce in the forces working on the surfaces and through these in the volume of the wear fragments. An observed increase in wear with atmospheric pressure was found to be accompanied by an increase in the number of wear fragments. This was attributed by Soda and his co-workers to the known effect of increasing atmospheric pressure in decreasing the fatigue life of materials.

Jahanmir et al. (26) have applied the delamination theory to the fatigue wear of composite surfaces. This theory postulates the existence in the wear track of a low dislocation-density zone which is softer than the sub-surface and deforms continuously with little work hardening. Thus, if a composite metal surface is created by depositing a thin layer of a softer metal on a harder substrate, heavy plastic deformation and delamination of the substrate may be prevented. When dislocations are generated by a rider on a composite material, these pile up at the interface between the soft metal film and its hard substrate, and as the rider moves on they escape through the surface of the wear track if the soft metal film is sufficiently thin. A thick soft film therefore wears until its thickness is reduced to the point where dislocations which develop in it begin to escape at a significant rate. At this stage the wear rate falls dramatically by a factor which may be as great as three orders of magnitude. From the results of wear tests with a crossed cylinder machine, this critical film thickness was found to be, in general, less than $1 \mu \mathrm{m}$ for gold, silver, cadmium or nickel on steel. Gold reduced wear both in air and in an inert atmosphere, whereas cadmium, silver and nickel reduced wear effectively in non-oxidizing environments only.

It is probable that wear occurs by both fatigue and adhesion mechanisms in practice, with one or the other predominating according to the particular circumstances. However, it is reasonable to anticipate that wear through fatigue will occur mainly under mild conditions.

\section{Lubrication of Gold}

The use of gold in sliding electrical contacts, as well as other tribological applications, calls for an understanding of the influence of atmospheric environments and lubricants on friction and wear performance. Buckley (27) showed that normal atmospheric contaminants, such as water vapour, affect the friction and surface deformation of gold. Water vapour physically adsorbed to gold reduced 


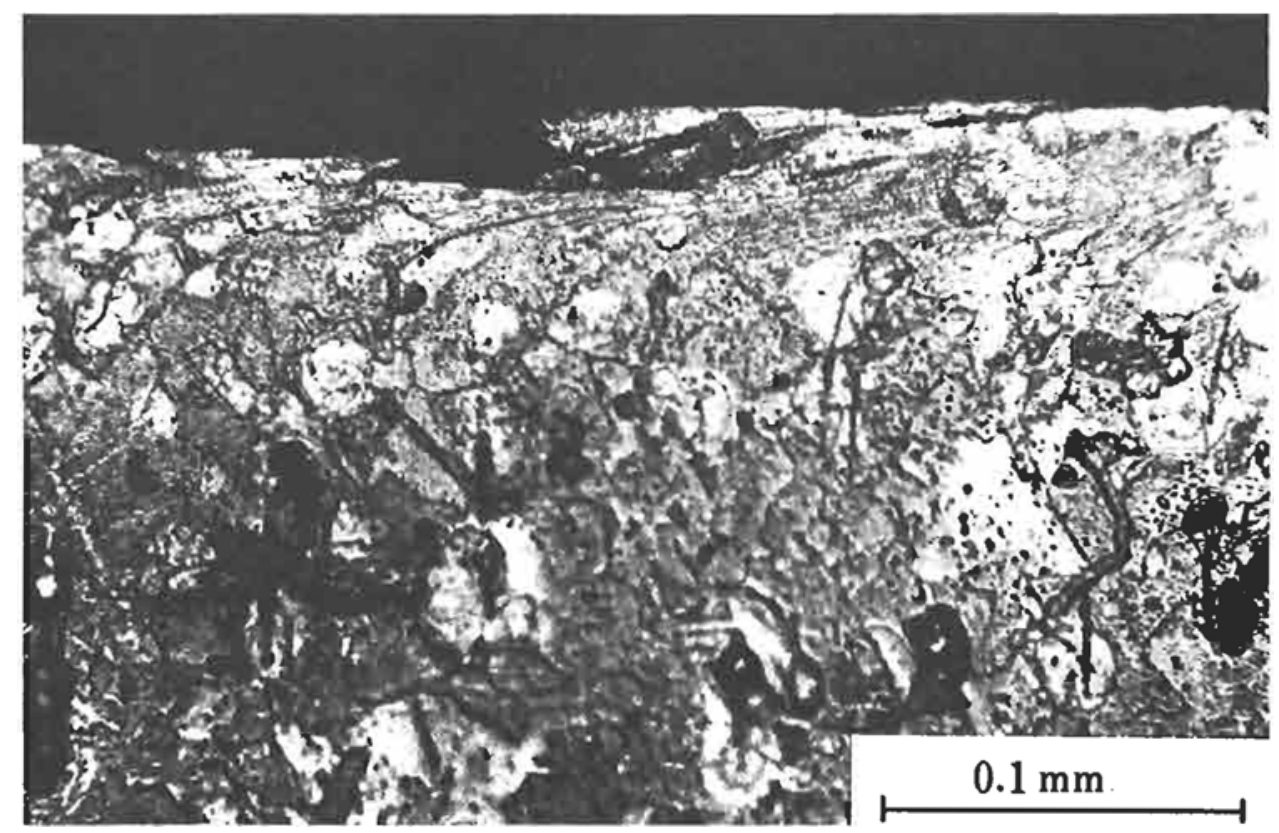

The conclusion of N. Soda, Y. Kinıura and A. Tanaka (25) that wear is caused by fatigue fracture in the sliding surfaces is substantiated by this micrograph of a worn nickel pin. These authors submitted the sample to sliding from left to right over $50 \mathrm{~m}$ at $335 \mathrm{~mm} / \mathrm{s}$ under a load of $25.5 \mathrm{~N}$ and under yormal atmospheric conditions belore sectioning and etching. The fatigue cracks extending along the line of flow of the metal are responsible for the liberation of wear fragments

friction at light loads and reduced deformation over the full range of loads studied. Miyakawa et al. (4) found that the endurance life of ion-plated gold films increased together with relative humidity $(\mathrm{RH})$ in air and reached a maximum in the range of 20 to 50 per cent RH. Above 60 per cent RH, the wear life of the films decreased gradually with increasing RH. This behaviour was attributed to water layers adsorbed on the gold. At 20 to 50 per cent $\mathrm{RH}$, these layers decreased adhesion of the gold to the rider while above 60 per cent RH they became thick enough to cause rupture of the gold film by penetration of water into cracks and by acceleration of oxidation of the rider metal.

Although adsorbed water vapour reduces the friction and deformation of gold, a gold surface is still not effectively lubricated in a moist environment and lubricants have been developed for use with gold in sliding applications. Antler (28) investigated the friction, wear and contact resistance of lubricated sliding gold contacts in low energy circuits. Experiments made with a rider-on-flat apparatus showed that the wear and friction of fluid-lubricated gold surfaces depends on both lubricant composition and viscosity. Halogen-containing fluids as a group are better lubricants than silicones. Hydrocarbons, fatty acids, fatty esters and related substances are intermediate in performance. Very viscous fluids induce hydrodynamic lift of the members and cause electrical noise. However, fluids having low viscosity also give noisy operation, which is associated with stick-slip and the formation of wear debris. Most lubricants tend to be about equally effective, provided their viscosities are between $10^{-4}$ and $10^{-3} \mathrm{~m}^{2} / \mathrm{s}$ at $25^{\circ} \mathrm{C}$. Antler concluded that thin lubricant films (of the order of tens of nanometers) offer considerable promise for successful use on contacts. Similar results were also obtained by Buckley (27) who found that the halides of gold all reduce friction and deformation. Of the halides, gold chlorides formed in situ are most effective and have proved superior to films of organic chloro compounds such as carbon tetrachloride.

Although hydrocarbons are frequently used for lubrication, they are not highly effective on gold because they are not chemisorbed on this metal. Hydrocarbon derivatives containing polar substituents are more effective and their chemisorption may be promoted if small concentrations of active metals are added to the gold. Thus, the addition of copper ( 0.25 to 5.0 weight per cent) to gold improves markedly the ability of stearic acid to lubricate its surface (27).

Antler (29) has reported upon several oil-soluble substances which give rise to solid lubricant films on gold tested in a four ball machine. For example, 5 per cent of di-n-butyltin sulphide in mineral oil gives rise to films of tin monoxide and tin monosulphide on gold. Dickert and Rowe (30) exploited this principle in developing a method of lubrication by oil-soluble and thermolabile compounds of metals such as gold, silver and copper. These decompose at hot rubbing 


\section{Steel Compositions}

The specified compositions of the steels referred to in this article are as follows:

52100: 0.98 to 1.10 carbon $/ 0.25$ to 0.45 manganese $/ 0.15$ to $0.30 \mathrm{silicon} / 1.30$ to $1.60 \mathrm{chromium} /$ balance iron, and 0.025 each of phosphorus and sulphur naximum weight per cent.

304: 18 to 20 chromiun $/ 8$ to 10.5 nickel/balance iron, and 0.08 carbon, 2.0 manganese, 1.0 silicon, 0.045 phosphorus and 0.03 sulphur maximum weight per cent.

440C: 16 to 18 chromium $/ 0.95$ to 1.20 carbon $/ 0.40$ to 0.65 molybdenum/balance iron, and 1.0 manganese, 1.0 silicon, 0.04 phosphorus and 0.03 sulphur maximum weight per cent.

1045: 0.38 carbon/0.73 manganese $/ 0.30$ silicon/0.08 copper/0.04 nickel/balance iron, and 0.04 phosphorus and 0.03 sulphur maximum weight per cent.

T-1: 17.25 to 18.75 tungsten $/ 3.75$ to 4.50 chromium $/ 0.90$ to 1.30 vanadium $/ 0.65$ to 0.75 carbon/ 0.20 to 0.40 manganese $/ 0.20$ to 0.40 silicon/balance iron weight per cent.

Circle C: 17 to 19 tungsten/9 to 11 cobalt $/ 1.0$ to 1.5 vanadium $/ 0.70$ to 0.85 carbon/balance iron, and 0.35 silicon, 0.60 manganese, 0.03 phosphorus and 0.03 sulphur maximum weight per cent.

surfaces to deposit in situ thin lubricant films of metal. Compounds that have this in situ metal filmforming property include gold, silver, copper and possibly mercury alkylphosphonates, gold alkylphosphates, and gold dialkylphosphorodithioates.

\section{Gold-Lubricated Ball Bearings}

Both caged and cageless ball bearings have been used for the testing of lubrication by gold. Caged ball bearings are the familiar standard type, but cageless ball bearings are often used in experiments because the harmful sliding friction between balls and cage can be completely excluded.

Tests have been performed at NASA's Goddard Space Flight Center (31), using R2-5 size ball bearings (bore diameter $3.175 \mathrm{~mm}$ ) in which both races and balls were electroplated with gold. The standard bearings in an induction motor were replaced by the bearings to be evaluated and the motor was placed in a test chamber. Test conditions were $10000 \mathrm{rpm}$ and $13 \mu \mathrm{Pa}$ at room temperature. Fully machined cages of five different material combinations and two separate sources (A and B) of gold deposits were employed. Coating A was 99.5 per cent gold with additives (nickel, indium and cobalt) to improve its adherence, hardness and brightness, and coating $B$ was almost pure gold. Bearings composed of a silver-plated Circle $C$ steel cage and gold A-plated races and balls showed the best performance - over 1600 hours life was obtained from them. Bearings using gold B had a life of only 300 hours. These results indicate that the adherence of gold $\mathrm{A}$ to the substrate was superior to that of gold B. Subsequently, the effects of four commercial gold coatings (the sources of which were designated as D, R, LR and T) on the bearing performance were studied. All other things being equal, golds D and LR which seemed to transfer in fine particles, eventually wearing thin and burnishing, and thereby providing effective metallic film lubrication, consistently outperformed golds $\mathrm{R}$ and $\mathrm{T}$ which showed relatively large particle transfer accompanied by flaking. These results revealed that electrodeposited gold films are not consistent in performance. Finally, bearings with six ball and race plating combinations of gold, barium and silver were studied. Bearings composed of gold L.R-plated balls, silver LR-plated races and a fully machined silver-plated Circle C steel cage were the most promising. In direct contrast, the combination of silver-plated balls and gold-plated races gave consistently poor performance. Bearing lifetime achieved with the other configurations, all involving barium coatings, fell in general between these extremes.

Lewis et al. (32) evaluated the performance of R-4 size $440 \mathrm{C}$ steel ball bearings (bore diameter $6.35 \mathrm{~mm}$ ) lubricated with several soft metal films and operating in vacuum $(0.13 \mathrm{mPa})$ at $3000 \mathrm{rpm}$. The lifetimes of bismuth-lead, lead, silver and gold films were 1650 , 1000,420 and 140 hours respectively. However, in low speed tests, gold films were equal to, or better than, many of the others. Harris et al. (33) studied the performance of cageless ball bearings lubricated with gold, silver, lead and gallium. The tests were conducted using separable angular contact ball bearings (bore diameter $6 \mathrm{~mm}$ ) of type $\mathrm{T}$-1 steel in which only the races were electroplated. Test conditions were. $3000 \mathrm{rpm}$ and $0.013 \mu \mathrm{Pa}$ at 50 to $60^{\circ} \mathrm{C}$. Lead films were by far the most successful and gold films gave poor and scattered lifetime results. However, the techniques used for applying the films were not investigated extensively and optimum conditions of deposition for the purpose may not have been obtained. The authors noted that gold might be capable of better performance than indicated by their results. Demorest and McMurtrey (34) applied sputtered gold and silver films to both races and balls of $\mathrm{R}-4$ size $440 \mathrm{C}$ steel ball bearings with reinforced tetrafluoroethylene (TFE) cages. Test conditions were $3600 \mathrm{rpm}$ and $1.3 \mathrm{mPa}$ at $29^{\circ} \mathrm{C}$. Bearings consisting of a reinforced TFE cage and uncoated races and balls gave over 6552 hours lifetime, whereas the combination of reinforced TFE cage and gold- or silver-plated races and balls gave a short lifetime of 700 to 3000 hours, thus showing that the reinforced TFE cage was detrimental to the lubricating action of gold and silver. 
These ball bearings illustrate two of the many combinations of coated and uncoated parts that are possible for the evaluation of the benefits brought abont by the use of gold coatings in tribological applications. In the caged ball bearing (top), the balls, the cage and both races are gold coated. In the cageless ball bearing (bottom), the balls only are plated with gold. Cageless ball bearings enable the study of the friction and wear behaviour of gold coatings under conditions where mechanical interaclions between the balls and the races only are involved
One of the more unusual applications for electrodeposits of gold with low coefficient of friction and high resistance to abrasion is in self-winding wrist watches of high quality. These brass spring housings have been coated with a gold-copper-cadmium alloy to prevent abrasion by the hardened steel spring of the watch. Additional details on this application were published in Gold Bulletin, $1979,12,(1), 34$.

Photograph by courtesy of Werner Flühmann A.G., Dïbendorf, Switzerland
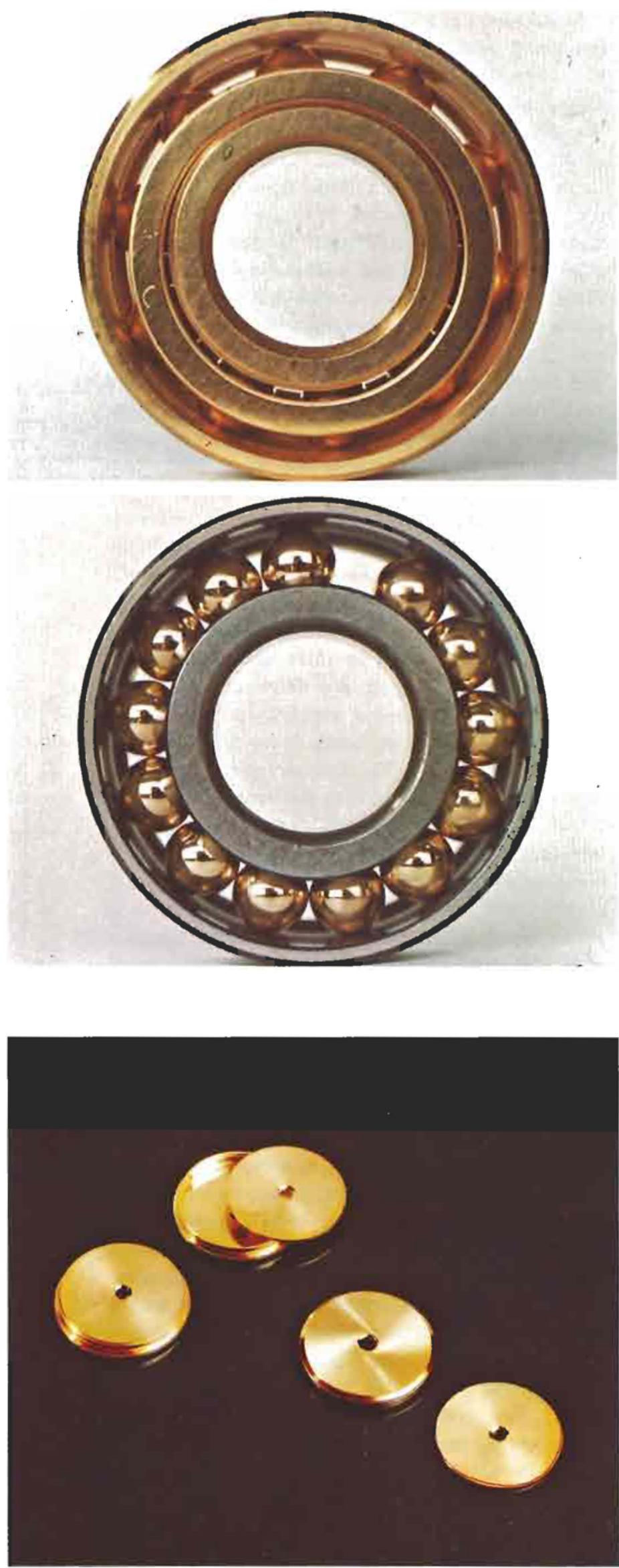
Miyakawa et al. (4) studied various combinations of ion-plated gold and silver films on angular contact ball bearings (\# 7204C, bore diameter $20 \mathrm{~mm}$ ). Caged ball bearings ceased to operate in a short time due to film wear and cageless ball bearings with goldor silver-coated balls exhibited the best performance. In air and in vacuum $(1.3 \mu \mathrm{Pa})$, the longest lifetime of the cageless ball bearings lubricated by gold was about 1500 hours at $2000 \mathrm{rpm}$. However, gold films gave poor reliability and scattered lifetime results. Furthermore, lifetime in vacuum decreased markedly as the test speed was increased from 2000 to 3000 $\mathrm{rpm}$. This poor performance of gold-coated ball bearings may be attributed to the high purity of ion-plated gold films which are thus too soft to provide wear resistance; the wear properties of gold, however, can be improved by alloying additions. Silver lubrication provided very short lifetimes in air - hours only but, in vacuum, coatings of silver outperformed those of gold and their reliability was good. No break in the silver film on the balls was found even after a total 800 hours operation at speeds of 2000,3000 and $4000 \mathrm{rpm}$. These results accord with those of sliding friction tests performed by these same authors and described above. Kessler and Mahn (35) have also found silver to be greatly superior to gold on ball bearings used in rotating anode $\mathrm{X}$-ray tubes operated in a vacuum of $0.13 \mathrm{mPa}$, between room temperature and $550^{\circ} \mathrm{C}$, and at speeds in the range of 3000 to $10000 \mathrm{rpm}$. Cageless ball bearings were used and the lubricant was a silver film applied to the balls only by means of a shim of silver placed between the halves of a split inner race and which protruded $0.05 \mathrm{~mm}$ above the race. Some of these bearings had lifetimes of 10000 hours or more.

\section{Concluding Remarks}

The friction and wear behaviour of soft metals has been investigated by many workers. Most such metals are poor lubricants, they melt at low temperature and are not resistant to oxidation. One outstanding exception is gold, which has good lubricating properties, melts at a sufficiently high temperature for many applications and does not corrode, even in aggressive environments. For these reasons, gold is the noble metal most extensively used for sliding electrical contacts.

The development of spacecraft has brought with it the challenge of providing lubrication in high vacuum and at high temperature. Thin films of gold may be used for this purpose at temperatures up to about $600^{\circ} \mathrm{C}$. Furthermore, the lubrication and wear properties of gold can be markedly improved by addition to it of one or more alloying elements. Thus, gold and its alloys are some of the most promising candidates for the lubrication of sliding metal parts, ball bearings and gears in special equipment for satellites and spacecraft. In recent years, lubrication by gold has also found application on sliding and rotating parts in ultra-high vacuum equipment such as evacuated and sealed electronic tubes with rotating assemblies, where it is important that there should be no outgassing from the lubricant. It may be predicted that lubrication by gold will be increasingly used under various conditions where conventional products fail to meet unusual requirements.

\section{References}

1 D. M. Mattox, Electrochem. Technol., 1964, 2, 295-298 E. W. Williams, Gold Bull., 1978, 11, (2), 30-34

2 T. Spalvins and D. H. Buckley, NASA, TN D-3040, 1965 and TM X-52305, 1967

$3 \mathrm{~N}$. Ohmae, T. Nakai and T. Tsukizoe, Wear, 1974, 30, 299-309

N. Ohmae, T. Tsukizoe and T. Nakai, Am. Soc. Mech. Eng. Trans., F. Lubr. Tecinol., 1978, 100, 129-135

4 Y. Miyakawa, M. Nishimura, M. Nosaka and Y. Miyawaki, f. Jpn. Soc. Lubr. Eng., 1977, 22, (12), 803-810; 1978, 23, (1), 51-66 and (2), 136-151

5 R. Takagi and T. Liu, Am. Soc, Lubr. Eng. Trans., 1967, 10, $115-123$

6 R. Takagi and T. Liu, Am. Soc. Lubr. Eng. Trans., 1968, 11, 64-71

7 A. Begelinger and A. W. J. De Gee, Am. Soc, Lubr. Eng. Trans., 1967, 10, 124-133

8 D. H. Buckley, NASA, TN D-7896, 1975

9 D. H. Buckley and W. A. Brainard, NASA, TN D-8394, 1977

10 D. H. Buckley, NASA, TN D-7930, 1975

11 D. H. Buckley, NASA, TN D-8230, 1976

12 D. H. Buckley, and W. A. Brainard, NASA, TN D-7986, 1975 D. H. Buckley, Am. Soc. Lubr. Eng. Trans., 1978, 21, 118-124 D. H. Buckley, NASA, TN D-7529, 1973

13 D. H. Buckley, NASA, TN D-5290, 1969; D.5351, 1969 and D-7018, 197I

14 K. Fujiwara, 7. Jpn. Soc. Lubr. Eng., 1977, 22, 37-44

15 K. Fujiwara, $\not$. $\not p n$. Soc. Lubr. Eng., 1977, 22, 109-116

16 K. Fujiwara, Wear, 1978, 51, 127-136

17 A. W. J. De Gee, Wear, 1965, 8, 121-132

18 A. J. Solomon and M. Antler, Plating, 1970, 57, 812-816

19 Y. Miyakawa, M. Nishimura and M. Nosaka, Y. Met. Finish., Special No., 1974, 191-200

20 W. H. Abbott and E. S. Bartlett, NASA, CR-1447, 1969

21 D. H. Buekley, NASA, TN D-2985, 1965

22 S. Enomoto, Y. Tsuya, G. Yaguchi, T. Ogani and R. Takagi, Preprint of the 22nd Annual Meeting of the Japan Society of Lubrication Engineers, May 1978, 177-180

23 H. R. Thornton and Z. R. Wolanski, Lubr. Eng., 1967, 23, $271-277$

E. W. Turns, Plating, 1977, 64, (5), 46-48, 52-54

E. W. Turns and R. D. Krienke, Plating, 1965, 52, 1149-1156

24 M. Antler, Proc. Inst. Mech. Eng, 1967-68, 182, (3A), 355-367 M. Antler, Am. Soc. Lubr. Eng. Trans., 1970, 13, 79-86; 1968, 11, 248-260 and $1962,5,297-307$

M. Antler, Wear, 1964, 7, 181-203

25 N. Soda, Y. Kimura and A. Tanaka, Wear, 1975, 33, 1-16; $1975,35,331-343 ; 1976,40,23-35$ and 1977, 43, 165-174

26 S. Jahanmir, E. P. Abrahamson II and N. P. Suh, Wear, 1976, 40, $75-84$ and $1975,32,33-49$

27 D. H. Buckley, NASA, TN D-4875, 1968

28 M. Antler, Wear, 1963, 6, 44-65

29 M. Antler, Ind. Eng. Chem., 1959, 51, 753-758

$30 \mathrm{~J}$. J. Dickert Jr, and C. N. Rowe, Am. Soc. Lubr. Eng. Trans., $1977,20,143-151$

$31 \mathrm{H}$. E. Evans and T. W. Flatley, NASA TN D-1044, 1962 D-1339, 1962; D-2101, 1963 and D-2304, 1964

32 P. Lewis, S. F. Murray, M. B. Peterson and H. Esten, Am. Soc. Lubr. Eng. Trans., 1963, 6, 67-79

33 C. L. Harris, J. E. Read, J. B. Thompson and C. I. Wilson, Lubr. Eng., 1968, 24, 57-63 and 131-138

34 K. E. Demorest and E. L. McMurtrey, Lubr. Eng., 1976, 32, $521-529$

35 G. R. Kessler and G. R. Mahn, Lubr. Eng., 1967, 23, 372-379 